\title{
Quantitative and Optimization of Anthocyanin Extracted from Pomegranate (Punica granatum) Extract by High-Performance Liquid Chromatography (HPLC)
}

\author{
Ridzwan Norhaslinda', Jumli Mimie Noratiqah' , Baig Atif Amin², Rohin Mohd Adzim Khalili1,3,4*
}

\section{Ridzwan Norhaslinda', Jumli Mimie Noratiqah', Baig Atif Amin'2, Rohin Mohd Adzim Khalili1,3,4*}

'School of Nutrition and Dietetic, Faculty of Health Sciences, University Sultan Zainal Abidin (UniSZA), Gong Badak Campus, Kuala Nerus, Terengganu, MALAYSIA.

${ }^{2}$ Faculty of Medicine, University Sultan Zainal Abidin, Medical Campus, Jalan Sultan Mahmud, Kuala Terengganu, Terengganu Darul Iman, MALAYSIA. ${ }^{3}$ Centre for Continuing Education (CCE), Universiti Sultan Zainal Abidin (UniSZA), Gong Badak Campus, 21300 Kuala Nerus, Terengganu, MALAYSIA. ${ }^{4}$ Institute for Community (Health) Development, Universiti Sultan Zainal Abidin (UniSZA), Gong Badak Campus, 21300 Kuala Nerus, Terengganu, MALAYSIA.

\section{Correspondence}

Dr. Mohd Adzim Khalili Rohin

School of Nutrition and Dietetic, Faculty of Health Sciences, University Sultan Zainal Abidin (UniSZA), Gong Badak Campus, Kuala Nerus, Terengganu, MALAYSIA

Phone No: +6-09-6688522

E-mail: mohdadzim@unisza.edu.my

History

- Submission Date: 15-02-2018;

- Revised Date: 14-03-2018.

- Accepted Date: 03-05-2018

DOI : 10.5530/pj.2018.4.107

Article Available online

http://www.phcogj.com/v10/i4

Copyright

(C) 2018 Phcog.Net. This is an openaccess article distributed under the terms of the Creative Commons Attribution 4.0 International license.

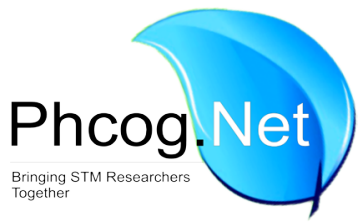

\section{ABSTRACT}

Objective: $P$. granatum is one of the oldest edible fruits of tropical and subtropical regions. This fruit had high antioxidant contained by hydrolysable tannins and anthocyanin compounds that give many health benefit properties. This study aims to quantify and optimized anthocyanin from $P$. granatum extract. Methods: A total of $50 \mathrm{~g}$ of the flesh was soaked into two different polar solvents; water and $50 \%$ ethanol within a ratio of $1: 10$; w/v for $24-\mathrm{hr}$. Then, three different methods of extraction were done and test each with HPLC analytical, respectively. Results: The validated method proved to be linear in the range of $5-30 \mathrm{ug} / \mathrm{mL}$ and with LOD and LOQ determined respectively for Cy3, Cy3, 5, Pg3, and Pg3, 5. The method also shows recovery (\%) close to 100 when accuracy was accessed. For samples, blender water extract had a higher composition of Cy3, Cy3, 5 and Pg3, 5 (22.77 \pm 8.82 mg/100 g e.p; $25.36 \pm 9.95$ $\mathrm{mg} / 100 \mathrm{~g}$ e.p; $11.16 \pm 5.85 \mathrm{mg} / 100 \mathrm{~g}$ e.p) content as compared to other. Conclusion: As a conclusion, the present methodology proved to be capable of detecting and quantifying Cy3, Cy3, 5, Pg3, Pg3, 5 in a single run. Also, comparatively the composition of each AC detected in blender water extract is significantly higher in value than the other methods. It should regard as a valuable source of antioxidant with the potential used for health benefits properties worldwide.

Key words: Cyanidin 3-glucoside, Cyanidin 3, 5-diglucoside, Pelargonidin 3-glucoside, Pelargonidin 3, 5-diglucoside.

\section{INTRODUCTION}

Anthocyanin (AC) are members of a class of watersoluble plant pigments that classified chemically as flavonoids. AC have C6 (A-ring), C3 (C-ring) and C6 (B-ring) flavonoid skeleton and structurally glycosylated or acylated. ${ }^{1}$ In pomegranate, AC is one of two major types of polyphenols compounds which account for the majority of antioxidant activity of the fruit. ${ }^{2}$ This activity is due to contain a number of phenolic hydroxyl groups attached to ring structures, which can exert antioxidant or radical scavenging activity through single electron or hydrogen atom donation. ${ }^{3}$

$\mathrm{AC}$ has been associated with wide range of anti-neurodegenerative, ${ }^{4}$ anti-inflammatory, anti-oxidative activities, ${ }^{3}$ and reducing the risk of cardiovascular disease (CVD). These potential health benefits had provoked an increasing demand for these compounds. In the pomegranate juice, cyanidin 3-glucoside (Cy3), cyanidin 3, 5-diglucoside (Cy3, 5), pelargonidin 3-glucoside (Pg3), pelargonidin 3,5-diglucoside (Pg3,5), delphinidin 3-glucoside (Dp3), and delphinidin 3,5-diglucoside $(\mathrm{Dp} 3,5)$ had identified as the main compounds responsible for the AC. ${ }^{1}$
Previous studies had observed AC identification during pre and post-storage, used two methods of juice extraction and others. ${ }^{1}$ Although much attention has focused on AC in pomegranate juice, the quantification of AC from different methods of juice extraction in Malaysia using a reliable technique is not studied yet. Thus, the objective of this study is to quantify and optimized for anthocyanin from pomegranate (Punica granatum) extract by highperformance liquid chromatography (HPLC)

\section{MATERIALS AND METHODS}

\section{Materials}

Cyanidin 3-glucoside from Sigma, Co. Chemical, St Louis (USA), Cyanidin 3, 5-diglucoside from Sigma, Co. Chemical, St Louis (USA), Pelargonidin 3-glucoside from Sigma, Co. Chemical, St Louis (USA), Pelargonidin 3, 5-diglucoside from Sigma, Co. Chemical, St Louis (USA).

\section{Extraction and Isolation of Punica Granatum}

Fresh pomegranate fruits were purchased from available sources in market Kuala Terengganu, 
Malaysia. The fruits were recognized for its shape, cultivars and morphological features. ${ }^{5}$ The fruits were then washed, peeled and separated into peel and flesh (aril with intact seeds).

A total of $50 \mathrm{~g}$ of the flesh was soaked into two different polar solvents; water and $50 \%$ ethanol within a ratio of $1: 10$; w/v for $24-\mathrm{hr}$. Then, all the extracts were filtered using Whatmann ${ }^{\circledR}$ No. 41 filter paper (pore size 20-25 $\mu \mathrm{m}$ ) and were then concentrated under reduced pressure at $40^{\circ} \mathrm{C}$. Finally, all the extracts were store at $-80^{\circ} \mathrm{C}$ until they were used for the analysis.

\section{High-Performance Liquid Chromatography AC Analysis Standard Compound Preparation}

$1 \mathrm{mg}$ of standard AC (Cyanidin 3-glucoside, Cyanidin 3, 5-diglucoside, Pelargonidin 3-glucoside, Pelargonidin 3, 5-diglucoside) were weighed and dissolved in 100\% methanol (HPLC grade) to give a stock solution of $100 \mu \mathrm{g} / \mathrm{ml}$. The stock solution was stored in vial HPLC and stored in $4^{\circ} \mathrm{C}$ until used for analysis. Peaks for AC composition were identified on the chromatogram by comparing the retention time and spiking test with AC standard.

\section{Identification and Quantification of AC by HPLC}

The method used by Miguel et al. ${ }^{6}$ with modifications were adopted in this study. The characterization of AC was performed by HPLC with a System Gold Programmable Detector Module 166-UV-Vis (Beckman Coulter, USA), using a LiChroCART $100 \mathrm{RP}-18$ column $(25 \mathrm{~cm} \times 0.4 \mathrm{~cm}$ i.d.: 5 um particle size; Merck (Germany). The mobile phases used were $0.001 \%$ T-fluoro acetyl acid (TFA) and DI water (A), 100\% methanol HPLC grade (B) and 100\% acetonitrile HPLC grade (C). Cy3 and Cy3, 5 were set using gradient 3, isocratic run for $20 \mathrm{~min}$. Pg3 and Pg3, 5 were set using isocratic run for $10 \mathrm{~min}$. The flow rate was $0.3 \mathrm{~mL} / \mathrm{min}$. Chromatograms recorded at an absorbance of $260 \mathrm{~nm}$. The concentrations of AC were calculated from standard curves of $\mathrm{Cy} 3, \mathrm{Cy} 3,5 \mathrm{Pg} 3$, and Pg3, 5 at six different concentrations (5 ppm, 10 ppm, 15 ppm, 20 ppm, $25 \mathrm{ppm}$ and $30 \mathrm{ppm}$ ). Injection volume was set at $15 \mathrm{uL}$ using an injector with a $20 \mathrm{uL}$ loop (Rheodyne, USA).

$\mathrm{AC}$ in samples was identified by comparing the chromatograms and retention times (RTs) of $\mathrm{AC}$ standard (Cy3, Cy3, 5, Pg3, and Pg3, 5) (Sigma, Co. Chemical, St Louis, USA) and used as a reference for quantification.

\section{Data Analysis}

The SPSS 20.0 software was employed for statistical analysis. Data were expressed as mean \pm SEM of three independent values.

\section{RESULTS AND DISCUSSION}

\section{Standards Validation}

Recovery (\%), Limits of Detection (LOD) and Limits of Quantification (LOQ) are terms used to describe the smallest concentration of a measure, and that can reliably measure by an analytical procedure. ${ }^{7}$ The parameters are to define the smallest concentration of an analyte that can be detected with no guarantee about the bias or imprecision of the result by an assay with LOD. Meanwhile, LOQ is the lowest concentration at which the analyte cannot be reliably detected but at which some predefined goals for bias and imprecision met. ${ }^{7}$

Based on Table 1, LOD and LOQ of each standard were assessed to determine the methodology sensitivity. Each standard was injected with $5,10,15,20,25$ and $30 \mathrm{ug} / \mathrm{mL}$ for this analytical procedure. LOD values were $3.32 \mathrm{ug} / \mathrm{mL}, 11.36 \mathrm{ug} / \mathrm{mL}, 11.32 \mathrm{ug} / \mathrm{mL}$, and $5.40 \mathrm{ug} / \mathrm{mL}$ for Cy3, Cy3, 5, Pg3 and Pg3, 5, respectively. While, LOQ values were $10.05 \mathrm{ug} / \mathrm{mL}$, $34.43 \mathrm{ug} / \mathrm{mL}, 34.29 \mathrm{ug} / \mathrm{mL}$, and $16.38 \mathrm{ug} / \mathrm{mL}$ for Cy3, Cy3,5, Pg3, and $\mathrm{Pg} 3,5$, respectively. This result was demonstrating that the method is sensible enough to determine $\mathrm{Cy} 3, \mathrm{Cy} 3,5, \mathrm{Pg} 3$, and $\mathrm{Pg} 3,5$ in the samples further.

AC analysis were used a RP- 18 column $(25 \mathrm{~cm}$ x $0.4 \mathrm{~cm}$ i.e.: 5 um particle size; Merck, Germany) and UV-Vis detector. This detector allows analysis of one wavelength at one time which is $260 \mathrm{~nm}$, as well verification of the chromatographic peak purity. The purity of interest AC in this study were 0.999 for $\mathrm{Cy} 3, \mathrm{Cy} 3,5, \mathrm{Pg} 3$, and $\mathrm{Pg} 3,5$, respectively. Meanwhile, the recovery (\%) was $100.73 \pm 4.77,102.31 \pm 10.84,101.67 \pm 8.58$, and 100.78 \pm 6.83 for $\mathrm{Cy} 3, \mathrm{Cy} 3,5, \mathrm{Pg} 3$, and $\mathrm{Pg} 3,5$, respectively.

\section{Samples Quantification}

The composition of AC using different extraction methods in both solvents of $P$. granatum extracts shown in Table 2 . The present study indicated four major AC were identified in each extraction method, namely, cyanidin 3-glucoside, cyanidin 3,5-diglucoside, pelargonidin 3 -glucoside, and pelargonidin 3, 5-diglucoside. In terms of quantity, the main AC inmost detected was Cy3, 5 with $25.36 \pm 9.95 \mathrm{mg} / 100 \mathrm{~g}$ e.p, followed by Cy3 (22.77 $\pm 8.82 \mathrm{mg} / 100 \mathrm{~g}$ e.p), $\mathrm{Pg} 3$ (18.18 $\pm 4.44 \mathrm{mg} / 100 \mathrm{~g}$ e.p) and Pg3, 5 (11.16 $\pm 5.85 \mathrm{mg} / 100$ g e.p).

From this study, it shows that blender (aril + seed) water has a higher composition of Cy3, Cy3, 5 and Pg3, 5 (22.77 $\pm 8.82 \mathrm{mg} / 100$ g e.p; 25.36 $\pm 9.95 \mathrm{mg} / 100$ g e.p; $11.16 \pm 5.85 \mathrm{mg} / 100 \mathrm{~g}$ e.p) content as compared to soaking (aril + seed) and soaking + squeezed (aril + seed). Whereas, the composition of Pg3 content in soaking + squeezed (aril + seed) water $(18.18 \pm 4.44 \mathrm{mg} / 100 \mathrm{~g}$ e.p) was found to be higher than soaking (aril + seed) and blender (aril + seed). Therefore, comparatively the composition

Table 1: Validation of optimization method from anthocyanin standard in HPLC.

\begin{tabular}{|c|c|c|c|c|}
\hline & Суз & Су3,5 & $\mathrm{Pg} 3$ & $\mathrm{Pg} 3,5$ \\
\hline Recovery (\%) & $100.73 \pm 4.766$ & $102.305 \pm 10.838$ & $101.670 \pm 8.583$ & $100.777 \pm 6.826$ \\
\hline Range (ug/mL) & $5-30$ & $5-30$ & $5-30$ & $5-30$ \\
\hline Correlation coefficient $\left(\mathrm{r}^{2}\right)$ & 0.999 & 0.999 & 0.999 & 0.999 \\
\hline Limits of Detection (LOD) (ug/mL) & 3.315 & 11.362 & 11.316 & 5.404 \\
\hline Limits of Quantification (LOQ) (ug/mL) & 10.045 & 34.430 & 34.291 & 16.377 \\
\hline Standard error for intercept & 0.132 & 0.515 & 0.752 & 0.273 \\
\hline Retention time (mins) & $7.738 \pm 0.021$ & $7.560 \pm 0.004$ & $7.831 \pm 0.031$ & $7.510 \pm 0.003$ \\
\hline Wavelength (nm) & 260 & 260 & 260 & 260 \\
\hline
\end{tabular}

${ }^{\star}$ Each value in the table was obtained by calculating the average of five experiments. 
Norhaslinda, et al.: HPLC Analysis of Anthocyanin from Pomegranate Extracts.

Table 2: Quantification of anthocyanin in P. granatum extracts ( $\mathrm{mg} / 100 \mathrm{~g}$ e.p).

\begin{tabular}{|c|c|c|c|c|}
\hline \multirow{2}{*}{$\begin{array}{l}\mathrm{S} \text { a } \mathrm{m} \mathrm{p} \mathrm{I} \text { e } \\
\text { Preparation }\end{array}$} & \multicolumn{4}{|c|}{ Concentrations (mg) } \\
\hline & Суз & Суз,5 & $\mathrm{Pg} 3$ & $\mathrm{Pg} 3,5$ \\
\hline \multicolumn{5}{|c|}{ Blender (aril + seed) } \\
\hline $50 \%$ ethanol & $11.71 \pm 3.18$ & $13.63 \pm 3.54$ & ND & ND \\
\hline $100 \%$ Water & $22.77 \pm 8.82$ & $25.36 \pm 9.95$ & $8.53 \pm 4.93$ & $11.16 \pm 5.85$ \\
\hline \multicolumn{5}{|c|}{ Soaking (aril + seed) } \\
\hline $50 \%$ ethanol & $15.19 \pm 2.11$ & $17.94 \pm 3.38$ & $2.09 \pm 0.95$ & $3.66 \pm 1.19$ \\
\hline $100 \%$ Water & $11.64 \pm 0.37$ & $10.84 \pm 0.62$ & $15.50 \pm 0.38^{b}$ & ND \\
\hline \multicolumn{5}{|c|}{ Soaking + squeezed (aril + seed) } \\
\hline $50 \%$ ethanol & $11.48 \pm 1.59$ & $15.32 \pm 1.02$ & $3.51 \pm 0.21^{\mathrm{a}}$ & $4.31 \pm 0.16$ \\
\hline $100 \%$ Water & $10.36 \pm 1.03$ & $10.85 \pm 1.00$ & $18.18 \pm 4.44$ & ND \\
\hline
\end{tabular}

ND: not detected

Data represent the mean \pm SEM of three independent experiments.

Statistical analysis was carried out using a One-Way ANOVA.

Different letters in the same column means a significant difference $(\mathrm{p} \leq 0.05)$.

of Cy3, Cy3, 5, Pg3, Pg3, 5 in blender (aril + seed) water is higher in value than the other methods.

AC provides the color of pomegranate fruit and juice, so this compound stability through juice processing is a major importance. It was reported previously in pomegranate juices; the diglucoside AC was more stable than the monoglucosides. ${ }^{8}$ This was parallel with present study and Dionex; ${ }^{9}$ Cy 3,5 and Pg3, 5 compositions are higher than Cy3 and Pg3. However, this was contrary to Miguel et al. ${ }^{6}$ in which there was a high decrease of $\mathrm{Cy} 3,5$ than $\mathrm{Cy} 3$ composition.

Also, the result of this study was parallel with Anahita et al. ${ }^{10}$ that pomegranate seed + juice had the highest total antioxidant activity $(47.00 \pm 5.50)$ than two other parts (seed and juice), separately. On the other hand, Mphahlele et al. ${ }^{11}$ Akhavan et al. ${ }^{12}$ and Fischer et al. ${ }^{13}$ had identified the individual $\mathrm{AC}$ in pomegranate extract, and the result was parallel with the present study. However, undetectable AC and its derivatives in the juices among those studies and present study are contrary to each other, and this may lead to several reasons. According to Akhavan et al. ${ }^{12}$ different methods of extraction used may affect the AC content of pomegranate juices as different parts and pressure introduced.

\section{CONCLUSION}

The optimization of HPLC methodology allowed simple and fast AC determination. The results demonstrated that the method is for quantitative AC, besides being linear and accurate when determined standards. On the other hand, all samples using different juice extraction and solvents can identify the Cy3, Cy3, 5, Pg3 and Pg3, 5 compounds in pomegranate. The composition of $\mathrm{Cy} 3, \mathrm{Cy} 3,5$, and $\mathrm{Pg} 3,5$ are higher in water extract with the preferable method of juice extraction blender (aril and seed). Comparatively, the method of juice extraction using blender shows the preferable of high composition among AC standards than the others.

\section{ACKNOWLEDGEMENT}

The authors would like to thank the Ministry of Higher Education, Malaysia and Universiti Sultan Zainal Abidin (UniSZA) for the financial aid (UNISZA/2014/FRGS/RR078) and the Faculty of Health Sciences for providing the facilities. The authors would also like to acknowledge all staffs from Teaching Laboratory 1, Faculty of Medicine and Faculty of Health Sciences, UniSZA.

\section{CONFLICT OF INTEREST}

The authors declare no conflict of interest.

\section{ABBREVIATIONS}

HPLC: High-Performance Liquid Chromatography; AC: Anthocyanin; LOD: Limit of Detection; LOQ: Limit of Quantification; UV-Vis: Ultraviolet Visible; Cy3: Cyanidin 3-glucoside; Cy3,5: Cyanidin 3,5-diglucoside; Pg3: Pelargonidin 3-glucoside; Pg3,5: Pelargonidin 3,5-diglucoside; SPSS: Statistical Package for the Social Sciences; SEM: standard error mean; DI: deionized water; \%: percentages; $\mu \mathrm{g} / \mathrm{ml}$ : microgram per milliliter; ${ }^{\circ} \mathbf{C}$ : degree Celsius; $\boldsymbol{\mu m}$ : micrometre; $\mathbf{n m}$ : nanometre; $\mathbf{w} / \mathbf{v}$ : weight per volume; C: carbon; g: gram; $\mathbf{m g / 1 0 0 ~ g ~ e . p : ~ m i l l i g r a m ~ p e r ~} 100$ gram edible portion; hr: hour; min: minutes; cm: centimetre; $\mathbf{u L}$ : microliter; $\mathbf{u g} / \mathbf{m L}$ : microgram per millilitre; $\mathbf{m L} / \mathbf{m i n}$ : millilitre per minutes; Mm: millimetre; ppm: parts per million.

\section{REFERENCES}

1. Zhao $X$, Yuan $Z$, Fang $Y$, Yin $Y$, Feng $L$. Characterization and evaluation of major AC in pomegranate (Punica granatum L.) peel of different cultivars and their development phases. European Food Research Technology. 2013;236(1):109-17

2. Mirsaeedghazi $H$, Emam DZ, Ahmadkhaniha R. Effect of frozen storage on the $\mathrm{AC}$ and phenolic components of pomegranate juice. Journal of Food Science and Technology. 2014;51(2):382-6.

3. Reis JF, Monteiro VVS, Gornes RS, DoCarmo MM, Da Costa GV, Ribera PC, et al. Action mechanism and cardiovascular effect of AC: A systematic review of animal and human studies. Journal of Translational Medicine. 2016;14(1):315-31.

4. Winter AN, Brenner MC, Punessen N, Snodgrass M, Brars C, Arora Y, et al. Comparison of the neuro-protective and anti-inflammatory effects of the AC metabolites, proto-catechuic acid and 4-hydroxybenzoic acid. Oxidative Medicine and Cellular Longevity. 2017;1-13.

5. Martinez NJJ, Melgarejo P, Legua P, Garcia-Sanchez F, Hernandez F. Genetic diversity of pomegranate germplasm collection from Spain determined by fruit, seed, leaf and flower characteristics. Peer Journal. 2016;4:e2214.

6. Miguel G, Dandlen S, Antunes D, Neves A, Martins D. The effect of two methods of pomegranate (Punica granatum L.) juice extraction on quality during storage at $4^{\circ} \mathrm{C}$. Journal of Biomedicine and Biotechnology. 2004;2004(5):332-7.

7. David AA, Terry P. Limit of Blank, Limit of Detection and Limit of Quantification. Clinical Biochemistry Revision. 2008;29(S1):49-52. 
8. Pedro AC, Granato D, Rosso ND. Extraction of AC and polyphenols from black rice (Oryza sativa L.) by modeling and assessing their reversibility and stability. Food Chemistry. 2016;191:12-20

9. Dionex C. Fast determination of $A C$ in pomegranate juice. Thermo Scientific. 2012. Retrieved on 3 December 2017 from: https://www.technologynetworks. com/applied-sciences/application-notes/fast-determination-of-anthocyaninsin-pomegranate-juice-228688.

10. Anahita A, Asmah R, Fauziah O. Evaluation of Total Phenolic Content, Total Antioxidant Activity, and Antioxidant Vitamin Composition of Pomegranate Seed and Juice. General Medicine. 2015;3:164
11. Mphahlele RR, Fawole OA, Mokwena LM, Opara UL. Effect of extraction method on chemical, volatile composition and antioxidant properties of pomegranate juice. South African Journal of Botany. 2016;103:135-44.

12. Akhavan $H$, Barzegar M, Weidlich $H$, Zimmermann BF. Phenolic Compounds and Antioxidant Activity of Juices from Ten Iranian Pomegranate Cultivars Depend on Extraction. Journal of Chemistry. 2015;1-8.

13. Fischer UA, Carle R, Kammerer DR. Identification and quantification of phenolic compounds from pomegranate (Punica granatum L.) peel, mesocarp, ari and differently produced juices by HPLC-DAD - ESI/MSn. Food Chemistry 2011;127(2):807-21.

\section{GRAPHICAL ABSTRACT}

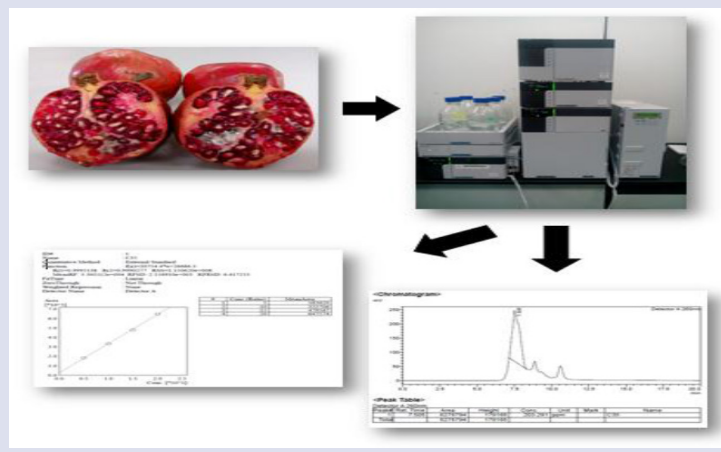

\section{SUMMARY}

- Selected standard anthocyanin were optimized and quantify using high-performance liquid chromatography (HPLC).

- Method optimization shows linear and accurate when determined standards.

- $\quad$ All samples using different juice extraction and solvents can identify each anthocyanin compounds in pomegranate.

- Comparatively the composition of each AC detected in blender water extract is significantly higher in value than the other methods.

\section{ABOUT AUTHORS}

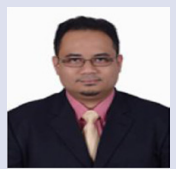

Dr. Mohd Adzim Khalili Rohin: Got his undergraduate degree and postgraduate degree from Universiti Putra Malaysia (UPM) in Food Study (1999 - 2002) and Community Nutrition (2003 - 2006). He finished PhD in Functional Food and Nutraceuticals $(2009$ - 2014) from Universiti Sultan Zainal Abidin (UniSZA). Work as Director Centre for Continuing Education and Senior Lecturer at Universiti Sultan Zainal Abidin (UniSZA). Currently on research functional food towards opioid dependence study.

Cite this article: Ridzwan N, Jumli MN, BaigAA, Rohin MAK. Quantitative and Optimization of Anthocyanin Extracted from Pomegranate (Punica Granatum) Extract by High-Performance Liquid Chromatography (HPLC). Pharmacog J. 2018;10(4):650-3. 